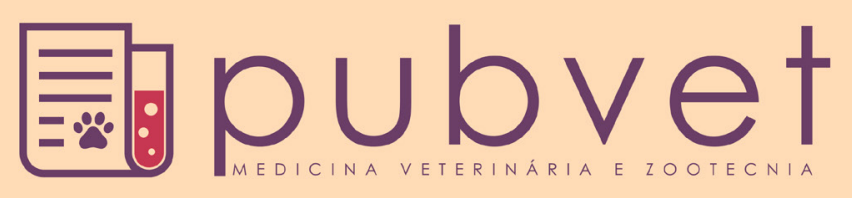

\title{
Confinamento para bovinos leiteiros: Histórico e características
}

\author{
Vania Corrêa Mota ${ }^{*}$, Alessandro Torres Campos $^{2}$, Flávio Alves Damasceno ${ }^{3}$, Everton \\ Augusto de Melo Resende ${ }^{4}$, Creuza Pedroso do Amaral Rezende ${ }^{5}$, Luiz Ronaldo de \\ Abreu $^{6}$, Teodora Vareiro ${ }^{7}$

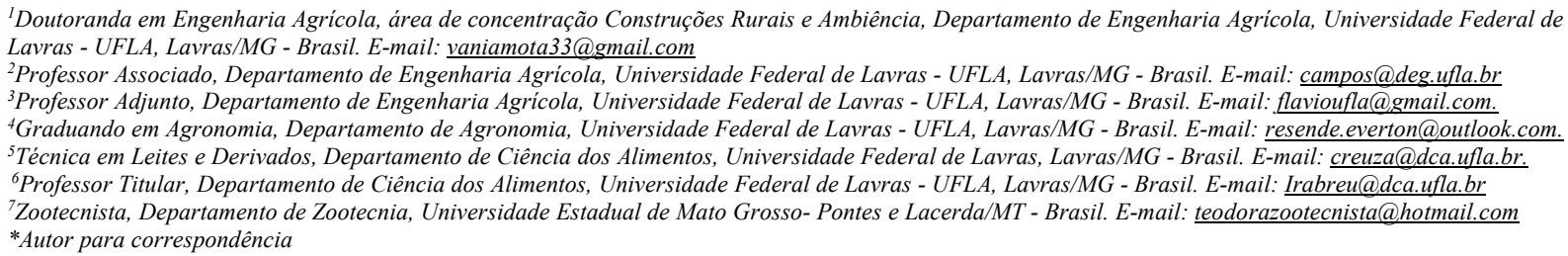

RESUMO. O regime de confinamento para a exploração de carne e leite, é pratica comum, recorrente e necessária em muitos países. Nos últimos tempos tornou-se crescente a preocupação com o planejamento das instalações destinadas aos confinamentos para bovinos leiteiros para melhorar o conforto e bem-estar dos animais. Dessa forma, esta revisão tem por objetivo descrever os tipos de confinamentos para bovinos leiteiros, existentes no momento, dando maior ênfase para as características construtivas de cada sistema. Os animais confinados podem ter um padrão aceitável de bem-estar e conforto à medida que instalações adequadas sejam fornecidas junto com boas práticas de manejo e sanidade animal. Com a pesquisa foi possível observar que a tendência é aumentar o número de confinamento no Brasil e no mundo devido à falta de grandes áreas de terras disponíveis próximas aos grandes centros urbanos, e devido as exigências dos consumidores.

Palavras Chave: Conforto animal, planejamento de instalações, sistemas de produção

\section{Feedlot for dairy cattle: history and characteristics}

ABSTRACT. The confinement regime for the exploration of meat and milk is a common, recurrent and necessary practice in many countries. In recent times there has been growing concern about the planning of facilities for confinement for dairy cattle to improve comfort and wellbeing of the animals. The purpose of this review is to describe the types of feedlots for dairy cattle, currently available, giving greater emphasis to the constructive characteristics of each system. Confined animals may have an acceptable standard of wellbeing and comfort as appropriate facilities are provided along with good animal health and management practices. An increasing trend of the number of confinement in Brazil and in of world could be noted based on this study. The reason for that is the lack of large areas of available land near urban centers and due to exigencies of consumers.

Keywords: animal comfort, facility planning, production systems

\section{El confinamiento de ganado lechero: historia y características}

RESUMEN. El sistema de estabulado para la explotación de la carne y la leche, es una práctica común, recurrente y necesaria en muchos países. Los últimos tiempos se ha convertido en una preocupación creciente para la planificación de las instalaciones para el confinamiento de ganado lechero para mejorar la comodidad, bien estar y salud de los animales. Por lo tanto, esta revisión tiene como objetivo describir el tipo de establos para 
ganado lechero, existentes hasta el momento, dando mayor énfasis a las características de construcción de cada sistema. Animales estabulados pueden tener un nivel aceptable de bien estar y comodidad, a medida que instalaciones adecuadas sean proporcionadas junto a las buenas prácticas de manejo y sanidad de los animales. Con la investigación se observó que la tendencia es aumentar el número de confinamientos en Brasil y en el mundo debido a la falta de grandes extensiones de tierra disponible cerca de los centros urbanos, y debido a las exigencias de los consumidores.

Palabras clave: conforto animal, planificación de instalaciones, sistemas de producción

\section{Introdução}

O regime de confinamento para a exploração de carne e leite é pratica comum recorrente e necessária em muitos países como: EUA, Israel, Japão entre outros. A principal razão para o uso desse sistema nesses países ocorreu devido às áreas limitadas e altos custos de terras próximas às áreas metropolitanas, bem como, o potencial limitado e a estacionalidade das pastagens para sustentar altas produções com rebanhos geneticamente melhorados (Novaes, 1993).

No Brasil, os sistemas de confinamento de bovinos ainda tem pouco significado em relação à produção total, a qual é tradicionalmente dependente do desenvolvimento das pastagens na época da estação chuvosa (Moreira and Prado, 2010, Prado and Prado, 2010). Em contraste, os países recordistas em produção de leite têm no confinamento a forma mais racional de exploração (Passetti et al., 2016).

Certamente, os sistemas de confinamento, em muito se diferenciam daqueles onde os animais têm acesso a pastagens (Rotta et al., 2010). No sistema de confinamento, as vacas são alimentadas no cocho, e necessitam de instalações confortáveis e funcionais que proporciona um ambiente melhor em termos de conforto térmico, para diminuir $\mathrm{o}$ estresse animal $\mathrm{e}$ consequentemente aumentar o seu bem-estar e sua capacidade produtiva (Rezelman, 1993).

No entanto, com os sistemas de confinamento para bovinos leiteiros, surgem novas dificuldades, como a elevação do custo de produção e a necessidade de mão de obra especializada, mas também aparecem novas oportunidades para manejar esse rebanho com conforto para permitir altas produções de leite sem implicar os aspectos reprodutivos e de saúde total dos animais (Pereira et al., 2010). Diante disso, o presente trabalho tem como objetivo, fazer uma revisão bibliográfica dos confinamentos para bovinos leiteiros, bem como, descrever sucintamente os tipos de confinamentos existentes no momento, dando maior ênfase para as características construtivas de cada sistema.

\section{Confinamento para bovinos leiteiros: histórico}

A partir de 1946, a tendência da grande maioria dos produtores de leite era a manutenção de seus animais em algum tipo de confinamento. Todavia, os galpões para criação de bovinos, teve seu início muito antes de 1880 , nesse período já existiam indícios desse tipo de construção que era utilizado para armazenar a colheita e o gado. Esta prática de utilização de celeiros era suficiente para iniciar uma nova tendência em direção a construir galpões para animais cada vez maiores, para o armazenamento de toda a colheita e de todo o gado sob o mesmo teto, e isso continuou até os galpões se tornarem cada vez mais extensos com dimensões acima que 25m (

Entretanto, os conflitos durante a II Guerra Mundial motivaram muitos agricultores a manter seus rebanhos em galpões. Nesse período, as fazendas eram historicamente baseadas na criação a pasto, porém com o inverno, devido a neve e ventos que prejudicavam os animais, forçou os produtores a melhorar o sistema de criação utilizado. Essa época se tornou um marco histórico que fornece um ponto de referência para a mudança na indústria de laticínios, pois a mecanização tornou-se popular em muitas indústrias, e para produtos lácteos não foi exceção (Rezelman, 1993).

$\mathrm{Na}$ década de 50 , os agricultores começaram a fornecer às vacas uma área de descanso chamada loose housing. Este método de manejo cresceu e se tornou popular, mas muitas propriedades de Minnesota e Wisconsin não aderiram, devido a adições frequentes de cama necessárias para manter as vacas limpas. E nesse período, muitas fazendas aderiram o confinamento durante todo o ano, usando pasto apenas para alimentar novilhas de reposição e vacas secas (Pereira et al., 2010).

O sistema de confinamento tie-stall foi facilmente adaptado aos estados de Minnesota e Wisconsin, em parte devido à tradição de silos 
verticais e descarregadores de silo que se tornou a solução tradicional para o armazenamento e a entrega de alimentos para os animais (Reis and Combs, 2001).

Em meados do século XX, muito resultados de estudos fornecidos aos produtores de leite sobre instalações animais, eram recomendadas para galpões com área de cama, onde todos os animais poderiam descansar. No entanto, pesquisadores e engenheiros procuravam alternativas para o rebanho diferente deste processo. Devido a isso, o free-stall foi criado (Misa, 2007). Com isso os galpões do tipo free-stall tornaram-se altamente recomendado por especialistas e se espalhou por vários países.

No Brasil nos anos 1980, a Embrapa Gado de Leite decidiu desenvolver sistemas de produção de leite no intuito de disponibilizar metodologias orientadas para a instalação e avaliação de modelos físicos como instrumento de pesquisa, de tal modo que entre 1982 e 1985 , cerca de 20 sistemas de produção de leite foram instalados nas cinco regiões fisiografias do Brasil, dentre estas se destaca a instalação em 1983, no Distrito Federal, em uma área de 100 ha cedida pela Embrapa Hortaliças, de um modelo de produção de leite com rebanho Holandês em regime de confinamento. Este sistema representava um esforço para assegurar a presença desta unidade de pesquisa no Centro Oeste (EMBRAPA, 2006).

No início de 1990, a Embrapa Gado de Leite instá-la um modelo físico de sistema de produção com um rebanho de gado Holandês em confinamento total, no Campo experimental de Coronel Pacheco. O sistema contava com o uso de tecnologias arrojadas para condições médias brasileiras, com animais de alto potencial genético para produção de leite e confinados em galpões do tipo free-stall (EMBRAPA, 2006).

Em meados de 1994 a 1997, em parceria com oito unidades de pesquisa da Embrapa e de cinco empresas estaduais, foi criado o projeto "Modelos Físicos de Sistema de produção de Leite", totalizando 18 sistemas de produção, sendo quatro em confinamento free-stall, que tinha como objetivo demonstrar a viabilidade econômica de sistemas inovadores de produção a produtores que queriam evoluir, e a partir de 1998, com o encerramento do projeto, os modelos físicos passaram a ser administrado pela gerência do Campo Experimental de Coronel Pacheco (EMBRAPA, 2006).
Com a ajuda da Embrapa alguns produtores aderiam ao sistema de confinamento, e o modelo free-stall logo ganhou destaque sendo construído em várias regiões, o modelo tie-stall, também foi construído em algumas propriedades, porém com menor relevância.

No ano de 2001, em Minnesota surge uma alternativa ao sistema loose housing, chamado compost barn. O compost barn surgiu devido à procura de produtores da região por um sistema que visasse mais o bem-estar dos animais e que fossem mais sustentáveis. Esse sistema possui uma área de cama que é revolvida no mínimo duas a três vezes ao dia, para manter a aeração aeróbia da compostagem. Desde então, instalações compost barn têm sido usadas em várias partes dos Estados Unidos e em outros países tais como o Japão, China, Itália, Holanda, Israel e recentemente no Brasil (Herrero, 2012).

No Brasil, o sistema compost barn iniciou na fazenda Santa Andrea em Itararé - SP. Existem controvérsias, onde produtores de Piracicaba-SP afirmam que o sistema compost barn iniciou em 2012, naquela região.

A principal particularidade do sistema compost barn é o processo de compostagem aeróbia da cama, que é induzida pela constante homogeneização dos dejetos animais associados a aeração da cama orgânica. Segundo Herrero (2012), os proprietários da fazenda Santa Andrea investiram na produção leiteira, com sistema compost barn devido ao menor custo de instalação e melhor conforto e bem-estar animal.

O sucesso foi tão grande que no final de 2014, o número de instalações compost barn teve um crescimento superior à trinta instalações no Brasil. No caso de Minas Gerais, algumas instalações compost barn já podem ser encontradas nas cidades de Sete Lagoas, Patrocínio, São João Del Rey, Santa Juliana, Lagoa da Prata, Santo Antônio do Monte, Juiz de Fora e Três Corações.

Esse crescimento, muito significativo ocorreu devido às instalações compost barn serem mais ecologicamente corretas e economicamente viáveis para os produtores de leite brasileiros que buscavam alternativas para aprimorar e modernizar suas instalações de produções.

Produtores de leite de vários países têm discutido diversos conceitos sobre as instalações compost barn em revistas técnicas especializadas, fóruns, congressos, indicando um enorme interesse sobre este novo sistema de alojamento 
animal. Apesar do aumento da popularidade do sistema compost barn no Brasil, o conhecimento científico sobre este sistema é escasso, necessitando, portanto, de mais estudos que possam auxiliá-los no processo de tomada de decisão e planejamento.

\section{Tipos de confinamento para bovinos leiteiros}

Como sistemas de confinamentos para bovinos leiteiros têm: baias individuais, denominado Tie Stall (TS), e os sistemas de estabulação livre com os modelos, Loose Housing (LH) e o Free Stall $(F S)$, que são os mais conhecidos pelos produtores, e o mais recente, Compost Barn (CB).

\section{a) Tie-stall}

No sistema tie-stall as vacas permanecem lado a lado, contidas em baias individuais a maior parte do tempo e são mantidas presas por uma corrente no pescoço, e recebem alimentação $100 \%$ no cocho; e, geralmente ficam soltas apenas na hora da ordenha quando fazem um pouco de exercício (Figura 1). É um sistema de alto investimento por animal alojado e de pouca eficiência de trabalho como limpeza, distribuição de alimentos e ordenha. O sistema de alimentação mais utilizado é o do fornecimento de alimentos concentrados separados da forragem, em função da dificuldade de mecanização. Normalmente são utilizados em rebanhos menores, onde a mão de obra é familiar (Reis and Combs, 2001).

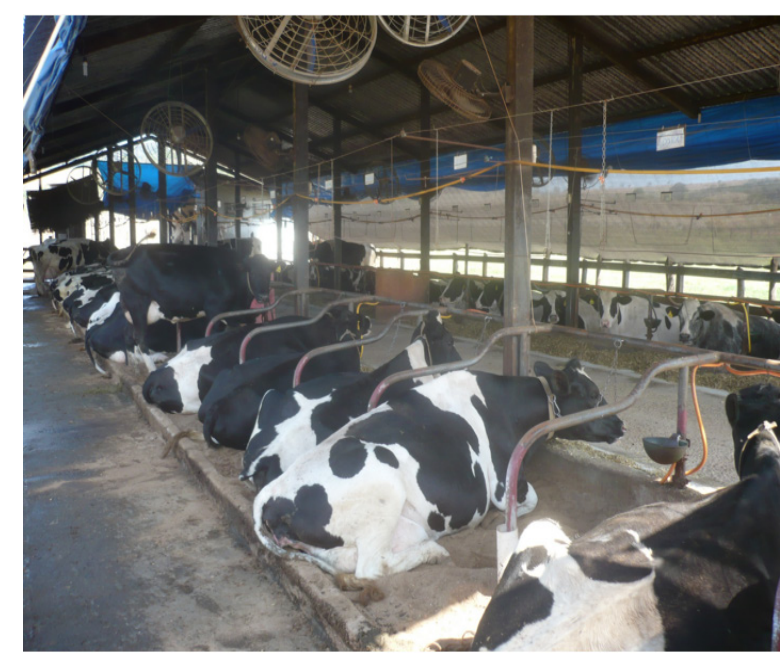

Figura 1. Confinamento no sistema tie-stall com animais da raça Holandesa, município de Ijaci/MG, Brasil.

Pereira et al. (2010) explicam que essa contenção, que prende os animais pode ser feita com canzis de madeira ou de tubos metálicos chumbados diretamente no piso de concreto, e ressalta que em geral a altura do pé-direito do galpão deve ser de, no mínimo 3 metros.

Segundo Mattos (1977), a água deve ser fornecida em bebedouros, que pode servir até dois animais, e a alimentação pode ser manualmente ou mecanicamente, até duas vezes ao dia, sendo que parte do concentrado pode ser fornecida na sala de ordenha. $\mathrm{O}$ autor ainda acrescenta que neste sistema a cama não precisa ser trocada diariamente, mas que as dejeções que caem em canaletas localizadas atrás dos animais devem ser limpas todos os dias para controle da higiene.

O sistema tie-stall é muito utilizado para rebanhos pequenos de até 60 animais em lactação, e para o sucesso deste tipo de instalação as baias devem possuir dimensões adequadas para a movimentação dos animais, sendo construídas de acordo com o tamanho dos animais, e o arranjo mais desejável é o de duas fileiras de baias, de modo que as vacas fiquem com a parte superior voltada para o corredor, chamada de área de serviço (Mattos, 1977). O tamanho recomendado para baias individuais do sistema tie-stall em relação ao peso da vaca, pode ser observado na tabela 1.

Tabela 1. Dimensões para baias individuais do tiestall.

Peso da vaca, kg Largura da baia, Comprimento da baia,

\begin{tabular}{lcc} 
& $\mathrm{cm}$ & $\mathrm{cm}$ \\
\hline 350 & 110 & 140 \\
450 & 115 & 150 \\
550 & 120 & 160 \\
650 & 130 & 170 \\
750 & 140 & 180 \\
\hline
\end{tabular}

Fonte: Adaptado de Mattos (1977).

O tie-stall é um sistema que exige mão de obra qualificada, e possui um elevado custo de investimento e infraestrutura, sendo utilizado com vacas de altíssima produtividade (Araújo, 2001). As vacas leiteiras permanecem limpas, mas como é reduzida a sua oportunidade de se exercitarem, aumenta a possibilidade de estresse dos animais.

\section{b) Free-stall}

No sistema free-stall, as vacas ficam soltas dentro de uma área cercada, sendo parte dividida em baias individuais, onde os animais permanecem lado a lado, e são forradas com cama que pode ser areia ou borracha triturada. As baias são destinadas ao descanso dos animais (Figura 2) e a outra parte da instalação é destinada para a alimentação e exercícios (Araújo, 2001) 
O tamanho recomendado para baias do sistema free-stall em relação ao tamanho da vaca, pode ser observado na tabela 2. O comprimento deve ser o mínimo para que o animal, ao deitar-se, permaneça com o úbere e as pernas alojadas internamente ao cubículo, enquanto as dejeções são lançadas no corredor de limpeza ou serviço (Campos et al., 2004). Mattos (1977) ainda reforça que quando bem dimensionadas, estas sempre permanecem secas e limpas por longo período (10 a 15 dias), de modo a gerar uma economia, do material de cama e da mão de obra.

Cecchin et al. (2014) estudaram o uso de camas em baias de um sistema free-stall, comparando o uso de colchão de borracha e de areia no recobrimento das baias, e verificou que houve maior preferência dos animais pela cama de areia para os comportamentos deitada em ócio e deitada ruminando, sendo que as vacas permaneceram mais tempo deitadas em cama de borracha somente nos períodos mais frescos (noite e madrugada) devido à temperatura da cama.

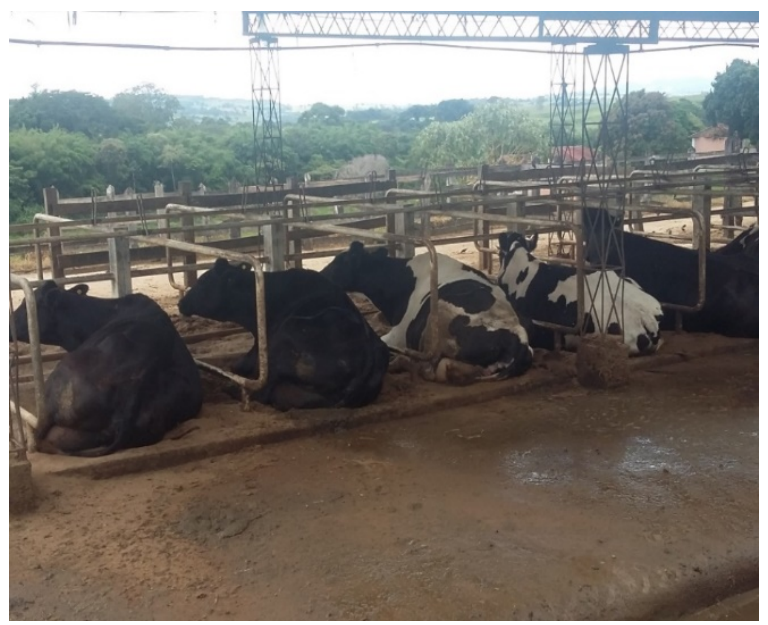

Figura 2. Confinamento no sistema free-stall com animais da raça Holandesa, no município de Ijaci, Minas Gerais, Brasil.

Tabela 2. Dimensões para baias no sistema free-stall. Peso da vaca, Largura, Comprimento, Altura, $\mathrm{cm}$ $\begin{array}{lll}\mathrm{kg} & \mathrm{cm} & \mathrm{cm}\end{array}$

\begin{tabular}{llll}
\hline $365-454$ & 100 & 183 & 100 \\
$454-500$ & 107 & 198 & 102 \\
$500-545$ & 112 & 208 & 104 \\
$545-682$ & 117 & 213 & 112 \\
$>685$ & 122 & 228 & 112 \\
\hline
\end{tabular}

Fonte: Adaptado de $\underline{\operatorname{Head}(1996)}$.

De acordo com Mattos (1977) o complexo de construção de uma instalação do tipo free-stall é constituída de quatro áreas, interligadas e independentes, que são: área de repouso, alimentação, ordenha e exercício. $\mathrm{Na}$ área de repouso que são construídas as baias individuais, com cama de material seco e macio de espessura de $10 \mathrm{~cm}$ e é na área de exercício que os animais devem dispor de uma área externa, com $10 \mathrm{~m}^{2}$ por vaca, construída de piso de concreto para facilitar a limpeza e melhorar a higiene dos animais.

O sistema free-stall foi recomendado e se tornou muito popular entre os produtores, devido ao seu manejo, ou seja, quando as vacas não estão sendo ordenhadas, elas podem ficar vagando livremente em um grande espaço aberto com chão de terra ou concreto e acesso fácilpara a alimentação que pode ser de feno ou silagem. $\mathrm{Na}$ hora da ordenha, as vacas podem ser treinadas para andar em uma sala de ordenha separada, onde terão acesso aos alimentos concentrados, enquanto estavam sendo ordenhadas.

Segundo Campos et al. (2004) os países em desenvolvimento, cada vez mais, adotam o sistema intensivo de produção animal, sendo o confinamento, em galpões com sistema free-stall, um dos preferidos pelos produtores para a criação de gado de leite.

Head (1996) afirma que uma das funções mais importantes de instalações do tipo free-stall é a de interceptar a radiação solar para reduzir a carga térmica no animal e permitir o manejo adequado para auxiliá-lo a manter homeotermia e, portanto, conforto para que o consumo de alimentos seja maximizado. As instalações adequadas permitem manter animais saudáveis e com mínimo de stress.

Nesse sentido, alguns pontos devem ser observados na construção desse tipo de estábulos que são: declividade do telhado, tipo de telha, altura do pé direito, espaço/animal, tipo de piso e ranhura, largura de corredores e etc. O projeto da instalação deve ser planejado de forma adequada, para permitir o máximo de conforto, movimentação tranquila e sua contenção prática e rápida, além de permitir a expansão para um número maior de animais.

\section{c) Loose housing}

No sistema loose housing, o confinamento dos animais ocorre em estábulos com área de repouso coletivo para gado leiteiro (Figura 3). Os animais embora confinados, ficam em áreas livres, para os exercícios com áreas cobertas para se protegerem do sol forte, chuva violenta e ventos frios, podendo ter liberdade de movimento e de direção (Vasconcellos, 1977). As vacas são levadas para 
áreas ou galpões separados para a ordenha e alimentação.

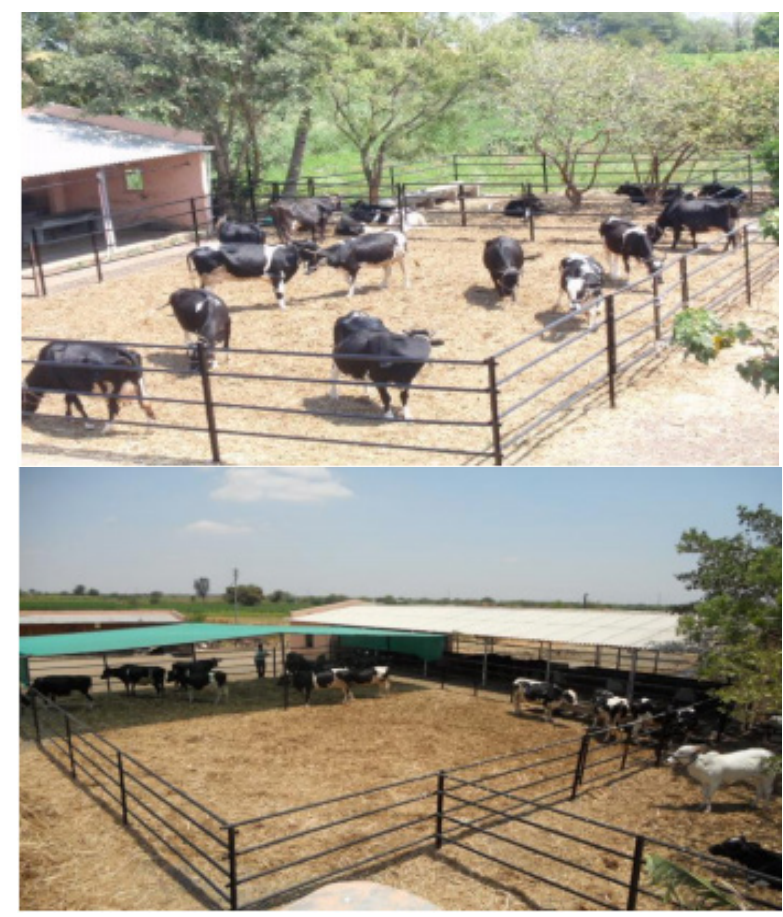

Figura 3. Confinamento no sistema loose housing, detalhe da área de descanso. Fonte: Shri (2012).

O sistema loose housing, por sua vez, é bastante popular em regiões mais secas dos Estados Unidos. Exige menor nível de detalhamento do sistema quando comparado ao free-stall, pois os animais permanecem em grandes currais equipados com área de descanso comum e sombreados. Nesse sistema, o capital investido por animal alojado é menor, sendo bastante difundido na região oeste dos Estados Unidos (Reis and Combs, 2001).

De acordo com Vasconcellos (1977) no sistema loose housing, as construções devem ter boa iluminação natural e boa aeração. Os animais devem ficar protegidos da incidência dos ventos do Sul. O pé-direito deve ter de 2,50 a $4,00 \mathrm{~m}$, possuir o piso de concreto armado ou concreto rústico (areia grossa), com espessura de $12 \mathrm{~cm}$ e declive de $4 \%$, na direção contrária à construção coberta. Segundo Witzel (1950) a área de repouso, chamada de área com cama, é um espaço onde as vacas podem descansar ou deitar em uma cama coberta com material seco. Ela deve fornecer abrigo contra os ventos frios, neve e chuva, que são as instalações cobertas que ficam nessa área. O chão de terra pode ser satisfatório para áreas de repouso, desde que tenham de 0,20 a 0,25 metros de inclinação para proporcionar uma boa drenagem, e com uma faixa pavimentada, ao longo de toda a frente aberta, sendo que a maior parte da lama ou esterco nos pés das vacas vai cair sobre esta abordagem pavimentada. Equipamentos como tratores podem ser utilizados para a remoção dos dejetos que funcionam de forma mais eficaz sobre esta faixa (Witzel, 1950).

A retirada do esterco da parte coberta deverá ser feita diariamente e da parte aberta somente o excesso, devendo-se deixar que o esterco cubra todo o piso, para evitar que o mesmo desgaste muito os cascos dos animais. Para melhor eficiência deve-se passar diariamente uma enxada rotativa puxada por um pequeno trator, na parte com serragem.

Os cochos devem ser todos colocados do lado de fora e cobertos, de maneira, a não atrapalhar a passagem do trator com carretas distribuidoras de alimentos secos e verdes, que deverá ser feita com rapidez e máxima facilidade. A retirada do esterco e a reposição da serragem molhada e suja deverão ser feitas diariamente, sem exceção (Vasconcellos, 1977).

Segundo Pereira et al. (2010), as áreas mínimas necessárias por animal no sistema loose housing deve ser de $2,8 \mathrm{~m}^{2}$ para a área coberta, $6,0 \mathrm{~m}^{2}$ para área de repouso, $8 \mathrm{~m}^{2}$ para área descoberta e para exercícios e $16,8 \mathrm{~m}^{2}$ para o total da construção.

\section{d) Compost barn}

O compost Barn é um sistema de confinamento alternativo do conhecido sistema loose housing, onde os animais ficam soltos e podem caminhar livremente dentro do galpão (Figura 4), visando primeiramente melhorar o conforto e bem-estar dos animais e, consequentemente melhorar os índices produtividade do rebanho (Damasceno, 2012, Black et al., 2013).

Segundo Damasceno (2012) as instalações compost barn, são sustentáveis e oferecem benefícios para as vacas, que têm mais liberdade de movimento (exercitar) e um amplo espaço onde podem deitar naturalmente. Nesse sistema quando as vacas estão em pé, além da maior interação social, elas passam mais tempo em uma superfície mais suave, que são as camas e com isso melhora o bem-estar da vaca e a sua saúde. O autor ainda acrescenta, que quando são devidamente conduzidos, mantendo o material de cama seco e revolvendo o mesmo no mínimo duas vezes ao dia, pode resultar em diminuição da contagem de células somáticas (CCS) do leite, vacas mais limpas, aumento da produção de leite e redução da claudicação. 


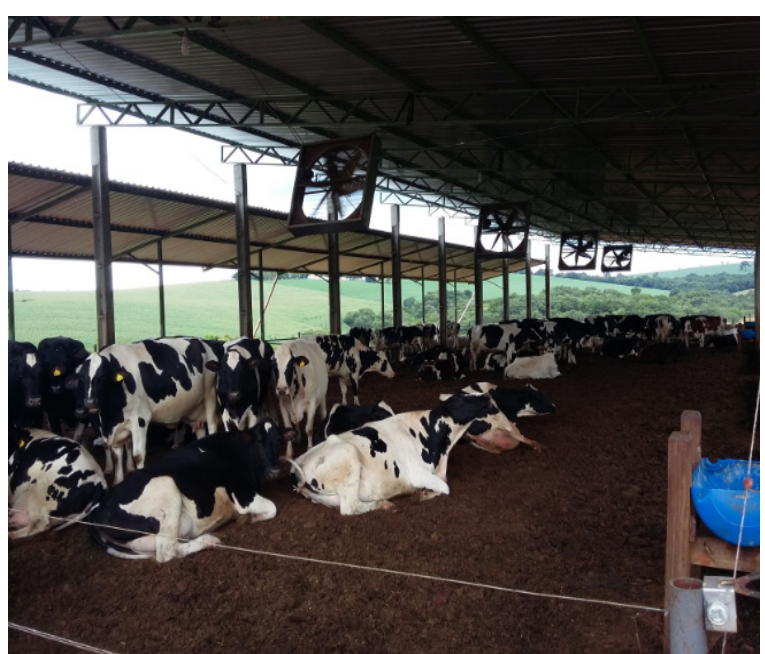

Figura 4. Sistema compost barn, município de Três Corações-MG. Fonte: autor.

O compost barn, assim como todo sistema de confinamento para bovinos leiteiros, exige cuidados e a observação de orientações técnicas para que sejam obtidos resultados positivos do ponto de visto produtivo e econômico, pode ser considerado para produtores que não possuem grandes áreas disponíveis para desenvolver a atividade leiteira como uma boa opção, sobretudo em locais onde a agricultura familiar é dominante (Brigatti, 2014). Neste sistema, as instalações devem ser bem projetadas e manejadas para terem sucesso, e isso inclui: uma estrutura bem projetada e um bom manejo da cama.

Normalmente, a instalação deve conter abertura na cumeeira, muretas laterais, um corredor de alimentação com piso de concreto (mínimo 4m), bebedouros fora da área de cama, dentre outros. As instalações devem ser abertas, priorizando a ventilação natural. Segundo Endres and Barberg (2007), Endres and Janni (2008) uma ventilação adequada deve ser realizada para que ocorra a troca de ar na instalação, sendo essencial para remover o calor das vacas bem como o calor e umidade que o material de cama gera, e no inverno essa troca de ar é necessária para remover a umidade desse material e estender o tempo entre as adições de cama.

A cama precisa ser revolvida frequentemente, a umidade ideal da cama e a densidade de animais devem ser controladas, e o material de cama tem que ser o apropriado para o conforto do animal e adequado para o produtor, com um custo acessível e disponível próximo a propriedade para facilitar a sua aquisição (Damasceno, 2012).

De acordo com Leso et al. (2013), o material de cama deve se manejado adequadamente para proporcionar uma superfície seca, confortável e saudável em que as vacas possam levantar e andar em uma superfície macia, os materiais de cama mais comumente usados são serragem, aparas de madeira e cavacos de madeira. Materiais de partículas pequenas, como a palha finamente processada, palha de milho e subproduto de palha de trigo também podem ser utilizados. Entretanto, deve ter cuidado com outros tipos de materiais de cama, tais como areia, esterco seco ou solo.

O material de cama deve ser revolvido para que ocorra um arejamento (Figura 5) para manter a condição aeróbia. Esse processo é geralmente realizado quando as vacas vão para a sala de ordenha. Esse material chamado de compostagem da cama refere-se a uma mistura de fezes e urina produzida pelas vacas e pelo material de cama orgânica (Leso et al., 2013). A atividade biológica gera calor e ajuda a secar a cama e quando a cama começa a aderir às vacas, um material limpo deve ser adicionado à cama. $\mathrm{O}$ fornecimento de material de cama deve estar prontamente disponível e limpo para não ser adicionado tarde demais e as vacas ficarem sujas.

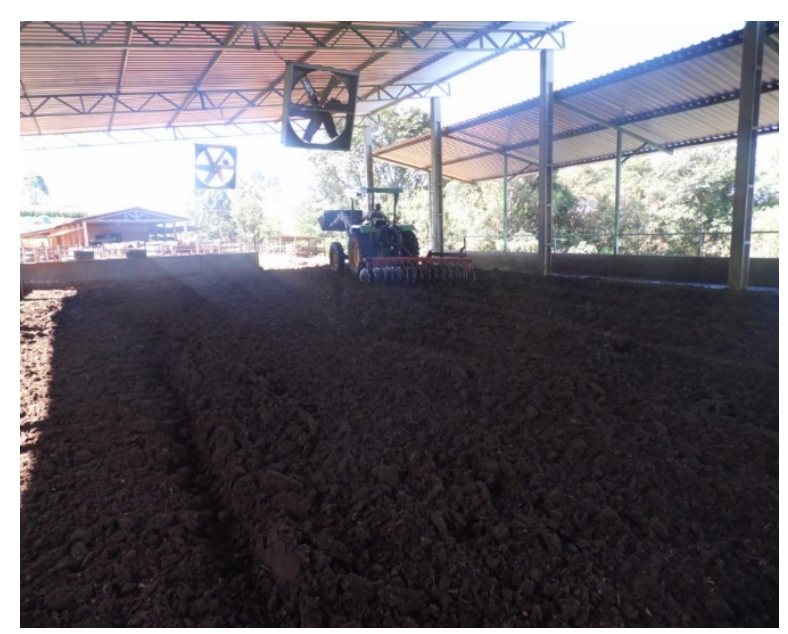

Figura 5. Revolvimento da cama no sistema Compost Barn - Município de Três Corações/MG. Fonte: Autor.

De acordo com Galama et al. (2011) o material de cama, quando misturado com as fezes das vacas, produz um fertilizante com quantidade de matéria orgânica para melhorar a fertilidade do solo. Black et al. (2013) acrescenta que um fator muito importante nesse sistema e manter as características físicos - químicas adequadas no substrato da cama a fim de promover a atividade microbiana aeróbia.

Tem sido observado que as instalações Compost barn com corredor de alimentação com piso de concreto tem gerado aproximadamente $30 \%$ a menos de efluente liquido, quando 
comparado com um sistema Free-stall tradicional. Neste caso, é necessária a construção de uma lagoa ou tanque para armazenamento deste efluente para depois ser bombeado e lançado no pasto. Por outro lado, alguns projetos têm retirado o corredor de alimentação com piso de concreto, aumentando, assim, a área de cama. Com isso, as instalações ficam com um menor custo inicial e reduzem também o efluente líquido proveniente de fezes e urina dos animais. Entretanto, o produtor deve ficar mais atendo a região de alimentação, pois normalmente existe a necessidade de maior manejo da cama nesta área.

Brigatti (2014) ressalta que o sucesso do sistema depende principalmente do manejo da cama, que consiste em seu revolvimento, e quando a compostagem é realizada de forma correta ocorre aumento da temperatura da cama, com redução da umidade e melhoria do processo de compostagem.

Os implementos agrícolas utilizados para o revolvimento da cama são: enxada rotativa, escarificador e grade aradora. O subsolador e usado para revolver as camadas mais profundas da cama, evitando que as regiões profundas se tornem anaeróbias, enquanto que a enxada rotativa não revolve as partes mais profundas da cama, mas tem o objetivo de quebrar os materiais que se tornam compactados, dessa forma, essa descompactação de partículas agregadas promove a oxigenação e aumenta a superfície de ação dos microrganismos presentes na cama, ocasionando um aumento na eficiência de compostagem.

\section{Vantagens e desvantagens dos sistemas de confinamentos para bovinos leiteiros}

Os sistemas de confinamento para bovinos leiteiros têm vantagens e desvantagens que serão descritas logo abaixo para os sistemas loose housing, tie-stall, free-stall e compost barn.

No sistema loose housing, o custo de construção é significativamente menor quando comparado aos demais. Neste sistema é possível fazer uma expansão da construção sem muita mudança. Ademais, existe a facilidade da detecção de animais no cio (Aland et al., 2002). Os animais ficam livres no interior da instalação, podendo expressar mais facilmente comportamentos naturais, tais como correr, deitar, levantar, dentre outros. Entretanto, esse sistema apresenta problemas com o escoamento dos dejetos da cama, caso a inclinação do piso na área de descanso não seja construída de forma adequada, podendo apresentar infestação de moscas (Witzel, 1950).

No sistema tie-stall podem ser encontradas as seguintes vantagens: vacas apresentam mais limpas; possibilidade de maior atenção a todos os animais; fácil mecanização; situação de trabalho do funcionário confortável; prático manejo, principalmente para rebanhos menores. Por outro lado, como desvantagens tem-se maior mão de obra no manejo dos animais; redução da oportunidade das vacas se exercitarem;alto custo de construção das instalações; possui pouca separação de vacas por lotes, com maior possibilidade de estresse animal.

No caso do sistema free-stall são vistas como vantagens a fácil mecanização, com custo operacional melhor; os animais se exercitam regularmente e apresenta uma alta flexibilidade para organizar diferentes manejos de alimentação e grupos. Como desvantagens, apresentam um custo de construção alto; menor atenção individual para o animal; maior competição entre os animais e vacas mais sujas por falha no manejo de limpeza (Araújo, 2001). No sistema compost barn, as vantagens são: as vacas possuem maior liberdade de escolha para movimentar e deitar na região da cama; os animais possuem menor possibilidade de apresentar problemas nos cascos, devido a instalação apresentar menor área com piso de concreto; e redução de dejetos líquidos (Damasceno, 2012). Ocorre também um aumento da detecção de cio, menor odor dos dejetos, diminui a incidência de moscas, além de fornecer melhores condições de trabalho aos produtores (Brigatti, 2014). Consequentemente, reduz os custos com o armazenamento de dejetos, sendo uma fonte poluidora menor, reduzindo a poluição do ar e da água. Para Galama et al. (2011) o sistema compost barn vem com oportunidades para melhorar a sustentabilidade na pecuária leiteira, tendo como desafio combinar mais espaço para os animais com menores emissões de gases e, ao mesmo tempo com um preço de custo reduzido (ou, pelo menos, um preço de custo estabilizado). Como desvantagens, tem-se a grande densidade por animal necessária (acima de $10 \mathrm{~m}^{2} /$ vaca), que pode se tornar um problema para o produtor caso ele queira trabalhar com um número muito grande de animais; dificuldade em encontrar material para a cama; e dependendo do projeto adotado pelo produtor, esse precisará manejar duas formas de dejetos (sólidos e líquidos) (Damasceno, 2012). 


\section{Considerações Finais}

Há tendência a aumentar o número de confinamento no Brasil e no mundo devido a falta de grandes áreas de terras disponíveis próximas aos grandes centros urbanos, e devido as exigências dos consumidores.

O conforto animal deve ser considerado, levando em conta o planejamento das instalações destinadas ao confinamento para bovinos leiteiros, o efeito do estresse térmico no desempenho e no comportamento animal, e o trabalho em equipe entre mão de obra especializada, pesquisadores e produtores. As vacas leiteiras confinadas podem ter um padrão aceitável de bem-estar e conforto, à medida que instalações adequadas sejam fornecidas junto com boas práticas de manejo e sanidade animal.

A eficiência dessas instalações vai depender da elaboração de um projeto adequado a cada região e situação, da construção, da manutenção, da escolha do tipo de instalação, principalmente, os custos, a durabilidade e a funcionalidade do sistema.

\section{Referências Bibliográficas}

Aland, A., Lidfors, L. \& Ekesbo, I. 2002. Diurnal distribution of dairy cow defecation and urination. Applied Animal Behaviour Science, 78, 43-54.

Araújo, A. P. 2001. Estudo comparativo de diferentes sistemas de instalações para produção de leite tipo $\mathrm{B}$, com ênfase nos índices de conforto térmico e na caracterização econômica. Faculdade de Zootecnia e Engenharia de Alimentos. Universidade de São Paulo, São Paulo.

Black, R. A., Taraba, J. L., Day, G. B., Damasceno, F. A. \& Bewley, J. M. 2013. Compost bedded pack dairy barn management, performance, and producer satisfaction. Journal of Dairy Science, 96, 8060-8074.

Brigatti, A. M. 2014. Compost Barn e a produtividade leiteira. IEPEC.

Campos, A. T., Klosowski, E. S., Santos, W. B. R., Gasparino, E. \& Campos, A. T. 2004. Caracterização do microambiente em secção transversal de um galpão do tipo" free-stall" orientado na direção norte-sul. Engenharia Agrícola, 24, 1-8.

Cecchin, D., Campos, A. T., Pires, M. F. A., Lima, R. R., Yanagi Junior, T. \& Souza, M. C. M. 2014. Avaliação de diferentes materiais para recobrimento de camas em baias de galpão modelo free-stall. Revista Brasileira de Engenharia Agrícola e Ambiental, 18, 109115.

Damasceno, F. A. 2012. Compost bedded pack barns system and computational simulation of airflow through naturally ventilated reduced model. Curso de Pós-Graduação em Engenharia Agrícola. Universidade Federal de Viçosa, Viçosa, Minas Gerais.

EMBRAPA. 2006. Gado de leite 30 anos de pesquisa e conquistas para o Brasil. Empresa Brasileira de Pesquisa Agropecuaria, Juiz de Fora, Minas Gerais.

Endres, M. I. \& Barberg, A. E. 2007. Behavior of Dairy Cows in an Alternative Bedded-Pack Housing System. Journal of Dairy Science, 90, 4192-4200.

Endres, M. I. \& Janni, K. A. 2008. Compost bedded pack barns for dairy cows. University of Nebraska-Lincoln, 1, 1-9.

Galama, P., Bokma, S., van Dooren, H. J., Ouweltjes, W., Smits, M. \& van Driehuis, F. 2011. Prospects for bedded pack barns for dairy cattle. Wageningen UR Livestock Research.

Head, H. H. 1996. Manejo de animais em sistema de estabulação livre visando maximizar conforto e produção. In: Moura, A. C. (ed.) Congresso Brasileiro de Gado Leiteiro Conceitos Modernos de Exploração Leiteira. FEALQ, Piracicaba.

Herrero, N. 2012. Produzir muito leite com Simental e Cruzamentos. Balde Branco, 28-31.

Leso, L., Uberti, M., Morshed, W. \& Barbari, M. 2013. A survey of Italian compost dairy barns. Journal of Agricultural Engineering, 44, 17.

Mattos, W. R. S. 1977. Sistemas de estabulação livre para bovinos. Simpósio sobre pecuária leiteira, 1, 123-139.

Misa, 2007. Dairy Your Way, The Minnesota Department of Agriculture.1-106.

Moreira, F. B. \& Prado, I. N. 2010. Sazonalidade na produção e qualidade de plantas forrageiras. In: Prado, I. N. (ed.) Produção de bovinos de corte e qualidade da carne. Eduem, Maringá, Paraná, Brasil.

Novaes, L. P. 1993. Confinamento para bovinos Leiteiros. In: Peixoto et. al. Bovino cultura Leiteira; Fundamentos da Exploração Racional.Piracicaba: FEALQ. 171 - 297. 
Passetti, R. A. C., Eiras, C. E., Gomes, L. C., Santos, J. F. \& Prado, I. N. 2016. Intensive dairy farming systems from Holland and Brazil: SWOT analyse comparison. Acta Scientiarum. Animal Sciences, 38, 439-446.

Pereira, E. S., Pimentel, P. G., Queiroz, A. C. \& Mizubuti, I. Y. 2010. Novilhas leiteiras. Graphiti Gráfica e Editora Ltda, Fortaleza, Ceará.

Prado, R. M. \& Prado, I. N. 2010. Suplementação em pastagem no período do inverno. In: Prado, I. N. (ed.) Produção de bovinos de corte e qualidade da carne. Eduem, Maringá, Paraná, Brasil.

Reis, R. B. \& Combs, D. 2001. Atividade leiteira nos Estados Unidos da América. In: Madalena, F. E., Melo, L. L. \& Holanda Júnior, E. V. (eds.) Produção de leite $r$ sociedade: Uma análise crítica da cadeia do leite no Brasil. FEPMVZ, Belo Horizonte, Brasil.

Rezelman, J. A. 1993. History of Barns, The crooked lake review.

Rotta, P. P., Prado, R. M., Moreira, F. B. \& Prado, I. N. 2010. Suplementação do perído do verão.
In: Prado, I. N. (ed.) Produção de bovinos de corte e qualidade da carne. Eduem, Maringá, Paraná, Brasil.

Shri. B. B. G. 2012. Modern Loose housing system with Sugarcane trash as a bedding material forcrossbredcows. 1.

Vasconcellos, P. M. B. 1977. Guia prático para o fazendeiro. NBL Editora, São Paulo.

Witzel, S. A. 1950. Loose housing for dairy cattle. Journal of Milk and Food Technology, 13, 14655.

\section{Article History:}

Received 9 February 2017

Accepted 16 March 2017

Available on line 5 May 2017

License information: This is an open-access article distributed under the terms of the Creative Commons Attribution License 4.0, which permits unrestricted use, distribution, and reproduction in any medium, provided the original work is properly cited. 